\title{
A Bioeconomic Foundation of the Malthusian Equilibrium: Body Size and Population Size in the Long-Run*
}

\author{
Carl-Johan Dalgaard ${ }^{\dagger}$ and Holger Strulik ${ }^{\ddagger}$ \\ Leibniz Universitat Hannover, Discussion Paper No. 373
}

ISSN 0949-9962

First version: September 2006. This version: January 2009

\begin{abstract}
Empirically there is a strong inverse association between population density and body size. It holds in human societies at different levels of economic development; in biology it is known as "Damuth's law", with bearing on all mammalian species. Yet this intriguing trade-off between size and number of people lacks a microfounded theoretical explanation. This paper develops a bio-economic growth theory that provides one. We hypothesize that individuals face a fundamental choice of dividing resources between the number of children and how well to nourish them. The costs of childbearing are conceived as the metabolic costs needed for carrying the child through weaning, as well as a more standard time cost. The metabolic cost component creates a natural trade-off: expanding fertility limits the amount of nutrition per child since parents need to consume more for themselves. In the long-run steady-state, body size, population size and per capita income is constant. Adult consumption is at the level of subsistence, which itself is endogenously determined.
\end{abstract}

Keywords: Subsistence, Nutrition, Metabolism, Population Growth, Ontogenetic Growth, Malthus.

JEL: O11, I12, J13.

\footnotetext{
${ }^{*}$ A previous version of this paper was circulated under the title: "Subsistence - A Bioeconomic Foundation of the Malthusian Equilibrium". We would like to thank seminar participants at the Universities of Ben-Gurion, Copenhagen, Cypress, Vienna, Hannover, Fribourg, Utrecht, and, at the Early Economic Developments Workshop, at the Council "Developing Countries" of the German Economic Association, and at the Econometric Society's European Meeting, 2007. The usual disclaimer applies.

${ }^{\dagger}$ University of Copenhagen, Department of Economics, Studiestraede 6, 1455 Copenhagen K, Denmark; email: carl.johan.dalgaard@econ.ku.dk.

${ }^{\ddagger}$ University of Hannover, Wirtschaftswissenschaftliche Fakultät, Königsworther Platz 1, 30167 Hannover, Germany; email: strulik@vwl.uni- hannover.de.
} 
"In Malthus's time, parents in most families had relatively few ways to spend on children since education, training, and medical care were all quite rudimentary. But an analysis of the demand for children that ignores various dimensions of their "quality" became less and less relevant with the economic development and other changes that began during the nineteenth century. It would be absurd now to omit education, training, and health when considering parental interest in children."

(Becker, 1992, p. 181)

\section{INTRODUCTION}

From a biological standpoint growth of the human species can be viewed as the rate of expansion in human body tissue. Naturally, total human body tissue depends on the number of people and their individual size. Whether the choice is made to produce more people, or bigger people, matters. Whereas more people (i.e., higher fertility) may be detrimental to growth, greater body size plausibly stimulates labor productivity. Yet no dynamic general equilibrium theory exists that allows for the systematic analysis of how both body size and the size of population are determined in the long-run. The present paper provides such a framework, focusing on the pre-industrial society.

In contemplating how body size and number of humans are determined in the long run, it is useful to be cognisant of a key stylized fact: Across all mammalian species a strong negative association is found between population density and (average) body size. In particular, this correlation holds within human communities at very different levels of economic development. In biology it is referred to as "Damuth's law" (Damuth, 1981, 1993). ${ }^{1}$

In line with the biological literature we interpret Damuth's law as reflecting the manifestation of a quantity-quality trade-off between size and number of offspring. To elucidate its microfoundations we hypothesize that individuals care about how many children they have, and how well they nourish them. The direct cost of child rearing is conceived as the elevated metabolic needs of the parent in terms of giving birth and supplying the offspring with nutrients until weaning. Taken together this creates a natural quantity-quality trade-off in terms of fertility and nutrition per child: A greater number of children increases the metabolic needs of the parent thus leaving less resources for child nutrition ceteris paribus. This mechanism generates an inverse association between family size and body size of the offspring, and a negative association between body size and population density.

\footnotetext{
${ }^{1}$ Section 2 discusses this evidence in detail.
} 
In existing demo-economic theories of growth the quantity-quality trade-off is perceived to be crucial for an appropriate understanding of long-run development patterns. The above Beckerquote illustrates why: during Malthusian times families arguably did not invest (much) in the quality of children, whereas they certainly do so today. ${ }^{2}$ This observation almost immediately suggests a clear demarcation line between "Malthusian stagnation" and the contemporary "sustained growth" regime. Namely, at the point in history where families started investing in child quality, substituting it for child quantity. Prior to this point investments in child quality were not (to any appreciable extent) undertaken by the family. This behavior can explain the durability of the Malthusian equilibrium: increasing productivity only translates into higher fertility, not into investments in the quality of the offspring. Absent accumulation of skills (the standard notion of child quality), diminishing returns to raw labor input ensure that living standards do not rise secularly. However, once households start investing in quality rather than the mere quantity of children, the economy ventures onto a trajectory characterized by rising living standards. Many demo-economic theories of growth draw on this logic. ${ }^{3}$

The proposed theory, in contrast, suggests quality investments have been made throughout history. In accordance with the empirical evidence we allow quality investments to have an economic pay-off; larger individuals are more productive. ${ }^{4}$ Yet, a take-off to sustained growth does not occur.

The model features overlapping generations. Individuals live for two periods; childhood and adulthood. Children are passive recipients of nutrition, determined by the parent, who is the economically active agent; we ignore matching in the marriage market and allow agents to reproduce asexually. The economic components of the model are fairly standard; a unique output good is produced using body size augmented labor, land, and technology. Since we are focusing on pre-industrial times, technology is assumed to be parametrically fixed; land is also a

\footnotetext{
2 "Malthusian times" refers to the period of human history during which income per capita levels stagnated on average. According to Clark (2007), Malthusian times for Western Europe would loosely speaking include the epoch preceding 1800. Galor and Weil (1999) puts the end of the "pure" Malthusian regime in Western Europe at about 1500, citing evidence of gradually (albeit incrementally) rising population size and living standards between 1500 and 1800 .

${ }^{3}$ Prominent contributions include Galor and Weil (2000) and Lucas (2002); see Galor (2006) for a survey. For evidence in favor of a quality-quantity trade-off in the specific sense of skills vs. family size see e.g. Rosenzweig and Wolpin (1980) and Hanushek (1992).

${ }^{4}$ See e.g., Fogel (1994, 1997), Behrmann and Rosenzweig (2004) and Weil (2007) for evidence on the positive link between body size and labor productivity.
} 
fixed factor of production. Accordingly, diminishing returns to labor input prevail. Aside from this the theory builds on three novel elements.

First, parents derive utility from quantity and quality (nutrition) of children. Both quality and quantity are normal goods; preferences are homothetic. Second, the metabolic rate of the parent is increasing in both body size and the fertility rate. The parent is required in each period to cover these needs. Whereas body size is predetermined at the time of optimization, fertility is a control variable. Theory and empirical evidence from biology provides this important bioecononomic constraint, right down to the functional form and its parameters. The substantive implication of the constraint is that if the number of children is expanded, the parent will need to consume more for herself leaving less resources for quality investments in the offspring. Aside from the metabolic (income) costs of children, we also admit a time cost. The third element is the law of motion for body size, which we derive from first principles, starting at the cellular level. The substantive implication of it is that more nutrition during childhood leads to larger adults; all body growth takes place during childhood.

These elements interact in the following way. A positive productivity shock will induce the parents to have more children and invest in more nutrition per child (quality). The better nourished children will grow up to be larger adults than their own parents. However, their elevated body size implies that they will be more energy requiring adults. This limits their ability to provide the same amount of nutrition per child that their parents provided, even if income per capita remains constant across generations. That is, even if rising body size were to fully compensate for a larger population vis-a-vis labor productivity. Thus the increase in body size is "checked" by rising needs of the parents, which puts downward pressure on nutritional investments (i.e., child quality) as well as expenditure on child quantity. Consequently growth does not take hold, and the economy remains in a state of stagnation. The steady-state is characterized by constant body size, population size and income per capita. Adult consumption is at the level of subsistence, which itself is endogenously determined.

Damuth's law emerges since increasing fertility raises parents' metabolism, which limits their ability to invest in quality (nutrition). This creates an inverse association between family size and average size of offspring (once grown up) that in the steady state translates into a negative association between population density and body size. 
Aside from elucidating the microfoundations for Damuth's law, the bio-economic model also allows for a series of interesting comparative static experiments. For instance, we study the impact on population density and body size from (incremental) technological innovations, and an increasing nutritional content in the diet.

These experiments are of interest for the following reason. Recent research has documented that population size indeed responded to changes in the technological environment in preindustrial times; technological progress prompted higher population density (e.g., Ashraf and Galor, 2008). In addition, in the centuries following a major innovation of the diet - the introduction of the potato - population density rose as a consequence (Nunn and Qian, 2008). At the same time, however, historians have documented that the average body size of Europeans exhibited no significant trend over the two millennia preceding the take-off into sustained growth (Kunitz, 1987; Koepke and Baten, 2005a). This represents an important challenge to the Malthusian interpretation of the pre-industrial society. The bio-economic growth theory developed below is consistent with these facts.

In addition, we are able to provide a microfounded account for the demo-economic change that occurred in the wake of the Neolithic revolution: working hours rose, population density rose, yet average body size fell. We argue that a central difference between hunter-gathering and the agrarian lifestyle lies in the time budget constraint. Whereas hunting and gathering is hard to combine with child rearing, the same is not true for agriculture where children may be brought into the fields during the work day. If the Neolithic revolution therefore lowered the marginal time cost of children, our model predicts that body size is reduced while working hours increase along with population density. This result is robust to the simultaneous emergence of higher productivity in the wake of the Neolithic revolution.

The present paper is related to the literature on growth in the very long run, which models Malthusian stagnation and the transition to modern growth (e.g., Galor and Weil , 2000; Lucas, 2002; Hansen and Prescott, 2002; see Galor, 2006 for a survey). These theories focus on the intricate and changing relationship between income and population during long-run development, and provide a theoretical explanation for the emergence of sustained growth. In contrast to the present paper, however, these studies ignore the evolution of body size, and assume the level of subsistence consumption is exogenous (if introduced at all). 
The present paper is also related to the anthropometric history literature, where height and fertility has been discussed in a unifying way. Weir (1993), in particular, provides a perspective on the quality-quantity trade-off that is similar to ours, and uses it to conceptually motivate an empirical analysis of the impact from the French fertility transition on height developments. More broadly, the anthropometric literature has long observed a link between changes in body size and movements in fertility, since nutrition during childhood influences not only adult stature but may also have a direct effect on fertility. For example, the age of menarche is reached earlier within well fed populations. A careful discussion is found in Komlos (1989), analyzing the period of take-off in the Habsburg Monarchy. Extending the theory below to include some of these additional mechanisms could be a potentially interesting topic for future work.

Finally, and perhaps surprisingly, it is worth observing that comparatively little attention seems to have been paid to the issue of stature in the context of demographic research. In a recent survey of the post 1995 literature employing data on height Steckel (2008, p. 6) remarks:

"[...]it is perplexing that demographers have made relatively little use of heights, or at least the mainline journals in the field contain few articles. [... Apparently [...] few researchers in demography or history analyze heights as part of their own research programs."

The present research suggests that this may indeed be a problematic state of affairs in that demographic patterns and anthropometric patterns, according to the developed theory, should be intimately related. Without taking stature into account it may be difficult to identify the determinants of fertility; like, for instance, the potential impact of income on fertility in Malthusian times. ${ }^{5}$

The paper proceeds as follows. In Section 2 we survey evidence on the link between fertility and body size, and its more aggregate manifestation, between population density and average body size. Section 3 develops the model. Section 4 proves existence and stability of the steady-state equilibrium and provides a series of comparative static results. Section 5 discuss comparative dynamics, and Section 6 concludes.

\footnotetext{
${ }^{5}$ Suppose body size is omitted in a regression aimed to examine the impact of wages on fertility. Then the coefficient on wages is likely to be biased towards zero; due to the discussed quantity-quality trade-off larger parents will tend to have fewer children (ceteris paribus), and larger individuals are, at the same time, likely to receive higher wages.
} 


\section{Size versus Number of Off-Spring: A quantity-Quality trade-OfF}

The most convincing evidence in favor of a quantity-quality trade-off is found in biology. At the level of the individual mammalian species, the inverse association between body size and rate of reproduction is by now well documented (Charnov and Ernest, 2006; Walker et al., 2008). Indeed, experimental studies manipulating offspring number or environment exist, which document the trade-off (Roff, 2002). A manifestation of this quantity-quality trade-off is found in "Damuth's law", which involves a negative correlation between body size and population density (Damuth, 1981; 1993). Figure 1, taken from Damuth (1993), provides an impression of the strength and pervasiveness of the correlation.

Figure 1. The figure shows population density (log) vs. Mass (log): 557 mammalian species

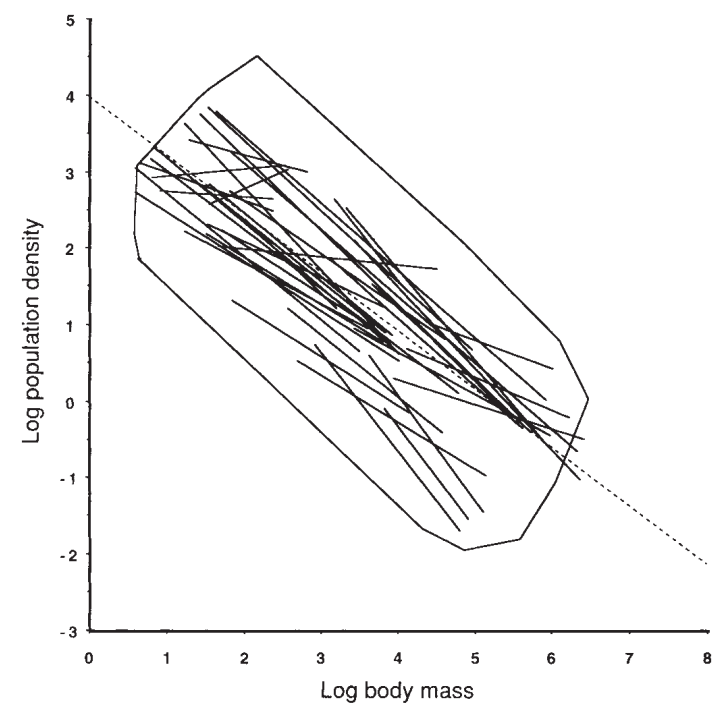

Notes. Dotted line: Full sample. Other lines: Species divided by feeding guilds, habitat and geo-zones. Estimates by OLS.

As seen from the figure, within each of the 557 mammalian species the negative correlation is found. While the position and slope of the line is somewhat species dependent, and varies across geo-zones as well, the overall negative association is visually obvious. Moreover, the coefficient on (log) body size, as reflected in the dotted "trend" line in the figure, is $-3 / 4 .^{6}$

In the context of human populations evidence of the size-number trade-off is also available. In the context of subsistence societies the inverse association between family size and size of the

${ }^{6}$ Hence, Damuth's law, for a varied sample of species, can be stated $d=d_{0} m^{-3 / 4}$, where $d$ is population density, $d_{0}$ is a constant and $m$ is body size (measured in kilograms). See Brown et al. (2004) for a survey of the empirical literature. 
offspring has received support by the work of Hagen et al. (2006), who examine the trade-off in the context of the "Shuar"; a subsistence society living in the tropical rainforests of Ecuador. Similarly, Walker et al. (2008) demonstrate a negative link between body size and family size across a sample of 16 subsistence-based societies. ${ }^{7}$

The most natural interpretation of Damuth's law is as a manifestation of a very basic form of a quality-quantity trade-off: the division of resources between nutrition per child and number of offspring. ${ }^{8}$ In micro data the trade-off should manifest itself as an inverse association between body size of siblings, and the size of the family. Moreover, since nutrition during childhood inevitably affects adult body size, and investments in the quantity of children will work so as to raise population size, one may anticipate a correlation between (average) stature and overall population density at the community level. Indeed, to the extent parents trade off nutrition for number of kids, one would expect to see an inverse association between body size and population density (at least, conditional on resource availability).

From the perspective of the present study the evidence amassed by biologists and anthropologists is of substantive importance, since it makes plausible that the size-number quality-quantity trade-off is likely a fundamental one. Moreover, the systematic link between reproduction and body size in economically primitive societies suggest that the trade-off most likely have been actively manipulated for a very long time; certainly before the take-off to sustained growth occurred in Western Europe. As a consequence, temporary income gains should be expected to translate into greater nutritional expenditure on children, implying "quality" investments.

In post-industrial societies evidence of the trade-off is found as well. In an early contribution Douglas and Simpson (1964) examined the results from a national survey of health and development in the UK. Specifically, the survey focused on 1,557 boys and 1,456 girls born in 1946. The physical development of these children was tracked and central health indictors were collected, including height, date of entry into puberty and age of menarche. In addition socio-economic indicators for the households were obtained, including occupation and educational background of the parents. This enabled Douglas and Simpson to categorize the families into social classes, ranging from "lower manual" to "upper middle". ${ }^{9}$ Figure 2 shows the association between the ${ }^{7}$ See Cole (2000) and Silventoinen (2003) as well.

${ }^{8}$ This is indeed the interpretation in biology. See e.g., Smith and Fretwell (1974), Charnov and Ernest (2006). ${ }^{9}$ In the "upper middle class" we find parents with a secondary education, families where the father has a nonmanual occupation, and where at least one of the parents was brought up in a middle class family with similar characteristics. In contrast, the "lower manual" group is characterized by the father being a manual laborer, by both parents only having primary education, and by upbringing; both parents were raised in a working-class 
mean body size of girls at age of 7 and the number of siblings in the family, as reported by Douglas and Simpson. ${ }^{10}$

Figure 2. Body Size of UK Girls at Age 7 and the Number of Siblings

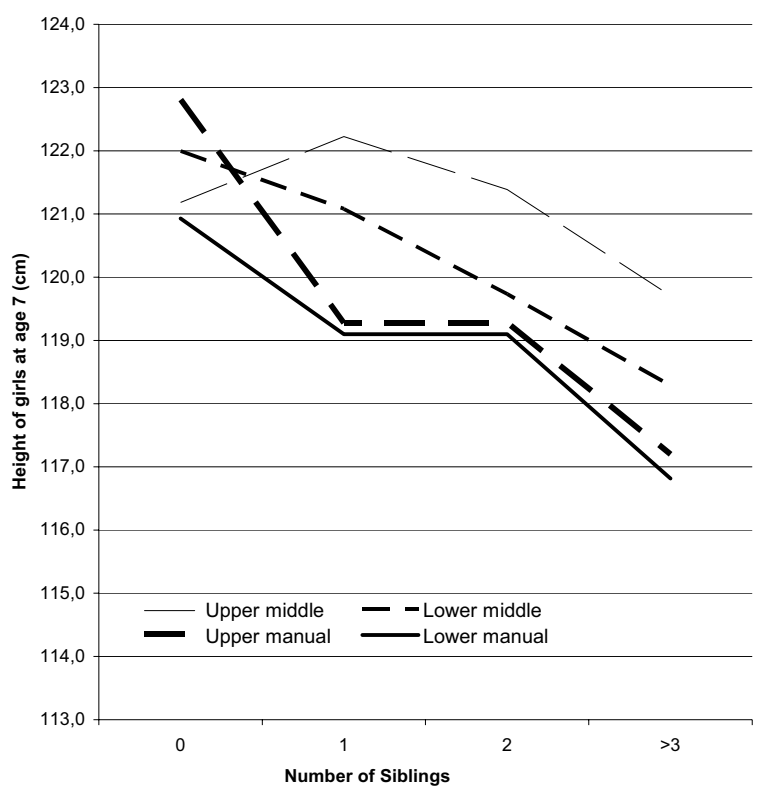

Notes. The individual lines refer to individual social classes, as defined in the text. Data source: Douglas and Simpson (1964), Table 7.

The general pattern that emerges is one where a large family size is associated with smaller mean body size of the offspring. In addition, for the size of the family given, the average body size of the offspring, measured by height, generally increases as the socio-economic circumstances improve. Douglas and Simpson document that similar patterns persist to the ages of 11 and 15 for both boys and girls.

The 1946 cohort has more recently been analyzed by Kuh and Wadsworth (1989). Their regression based analysis confirms the general impression conveyed by Figure 2; conditional on a host of environmental factors, each additional sibling implies a reduction in mean height of about $6 \mathrm{~mm}$.

At a higher level of aggregation Weir (1993) demonstrate a strong negative association between height and fertility rates across regions in France during the period 1840-1911. Following up on

family. Between these two extremes we find the "lower middle class" and "upper manual class"; these groups are differentiated from "upper middle class" and "lower manual class" mainly by their educational attainment.

${ }^{10}$ The picture for boys is very similar. 
Weir's findings, Schneider (1996) documents similar patterns across nine European countries, covering the period 1750-1920. Controls for health and income does not overturn these findings.

In light of this evidence it is of interest to inquire whether these patterns have left a "Damuth's law" pattern, when a cross-section of countries is considered. To examine this issue we obtained data for population density from World Development Indicators. In the present context we consider the year 2000, due to the availability of data on body size. Data on body size were obtained from Demographic and Health Surveys 2006. This database has recently been used by Akachi and Canning (2007) to explore health determinants in Sub-Saharan Africa. In the present context we utilize the information collected on body size of women, measured by their weight. ${ }^{11}$ The data pertains to the 1990 s, and if multiple surveys were made in a single country we use the data point closest to 2000. This leaves us with 50 country observations on population density and body size. ${ }^{12}$ The countries in our sample are all poor or middle income ones (see Appendix A for a listing).

The simple correlation between log body size and log population density is -0.31 , significant at the $5 \%$ level. Figure 3 illustrates the pure correlation between log body size (measured by weight) and log population density in our sample.

Naturally, one may wonder whether this correlation represents the macro counterpart to the trade-off found at the micro level, or whether it is a spurious correlation due to lack of control for intervening variables; income, mortality etc.

Table 1, columns 1-4, shows the results from estimating the association between body size and population density, while conditioning on log income per capita in 2000, infant mortality in 2000 and $\log$ calorie consumption per person per day in 2000. The correlation between density and body size is robust to the inclusion of these controls. ${ }^{13}$

While the inclusion of calorie consumption in the specification does provide some control for diet's influence on population size, it probably only does so imperfectly. Aside from macronutrients like calorie intake, micronutrients (such as various vitamins) also matter for fertility, as well as for body size. In addition, it is known that the composition of the diet tends to change during development. As a result, we also attempt to control for the diet in a more detailed

\footnotetext{
${ }^{11}$ Using data one height yields similar results, see footnote 15.

${ }^{12}$ The survey data is available from http://www.measuredhs.com.

${ }^{13}$ Calorie consumption per person, per day, is obtained from the FAO statistical Yearbook, and refers to the years 2001-2003. Data is found at: http://www.fao.org/ES/ESS/yearbook/vol_1_1/site_en.asp?page=consumption. Data on (PPP) GDP per capita and infant mortality is from World Development Indicators.
} 
Figure 3. Log Population density vs log body size: 50 less developing countries

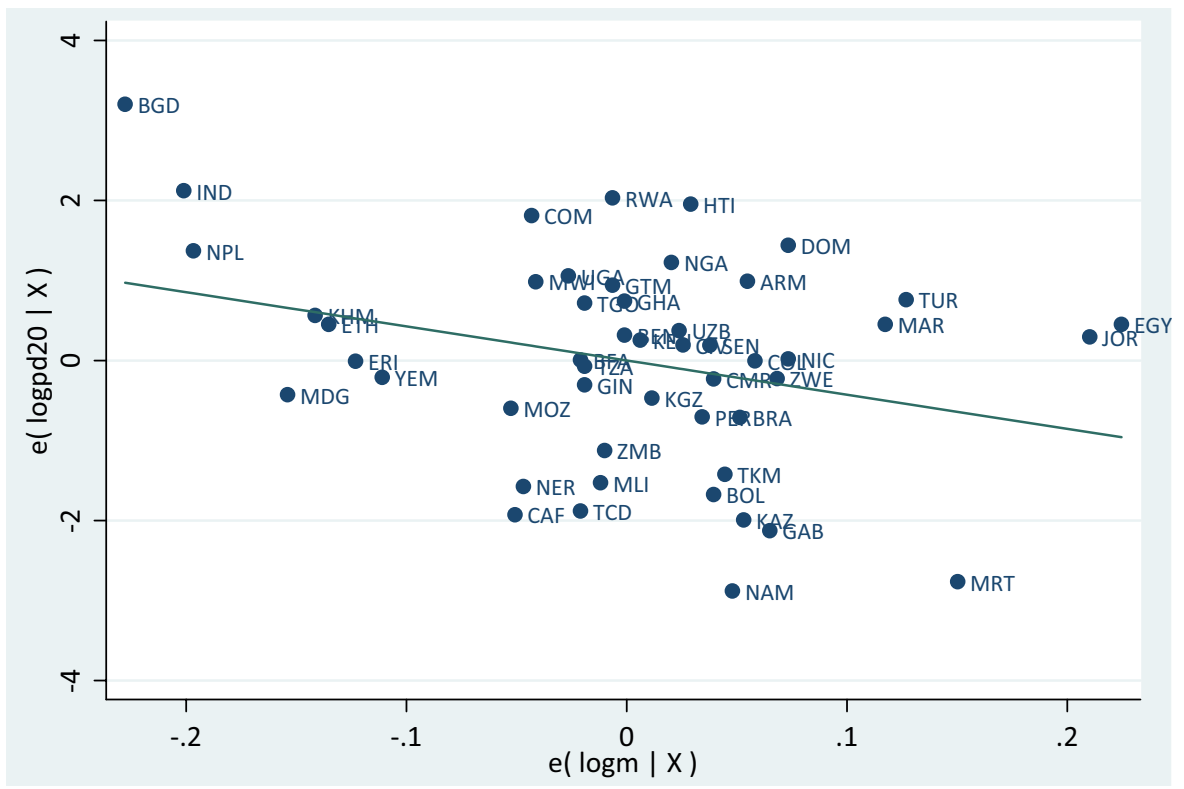

Notes: The Figure shows the association between population density and body size, conditional on a constant. Population density is taken from World Development Indicators, 2005. "Body size" refers to average weight in $\mathrm{kg}$; the countries are selected solely on the basis of availability of data. The underlying data source is Demographic Health Surveys. The year is 2000.

manner. Specifically, we obtained data from the FAO Statistical Yearbook on the share of various dietary components of food consumption. The categories are: cereals (CER); vegetable oils (VEG); sugar and sweeteners (SUG); meat and offals (MEAT); roots and tubers (ROOT); milk, eggs and fish (MILK); fruits and vegetables (FRU); animal fats (AFAT); pulses (PUL), and "others". ${ }^{14}$ The last category is excluded in the regression, to avoid perfect collinearity.

The results from including this information in the regression are reported in column 5 . The central result is that the negative correlation between body size and population density is robust to a more rigorous control for diet. In fact, when the composition of the diet is controlled for the association is strengthened, in the sense that body size is significant at the $1 \%$ level. ${ }^{15}$ Note also that the specification in column 5 does a fairly good job at motivating the variation in the data (albeit multicolliniarity renders a number of the dietary coefficients insignificant); the $\mathrm{R}^{2}$ is 0.74 .

\footnotetext{
${ }_{14}$ The data can be downloaded from www.fao.org/statistics/yearbook/vol_1_1/pdf/d02.pdf

${ }^{15}$ Data for height can also be obtained from Demographic and Health Survey 2006. The pure correlation between this measure of body size, and population density, is slightly higher than that involving weight: -0.4 , and significant at the $1 \%$ level. In the multivariate setting the results are slightly weaker. In a specification identical to that of Table 1, column 5, the coefficient for $(\log )$ height is -13.8 , with a p-value of 0.084 .
} 
Table 1. Population Density vs. Body Size in a Cross-Section of Countries

\begin{tabular}{|c|c|c|c|c|c|c|}
\hline $\begin{array}{l}\text { Independent } \\
\text { variable }^{a}\end{array}$ & $1^{b, c, d}$ & 2 & 3 & 4 & 5 & $6^{e}$ \\
\hline Log (body size) & $\begin{array}{c}-4.26^{* *} \\
(2.11)\end{array}$ & $\begin{array}{c}-5.04^{* *} \\
(2.51)\end{array}$ & $\begin{array}{c}-6.10^{* * *} \\
(1.93)\end{array}$ & $\begin{array}{c}-6.69 * * * \\
(2.44)\end{array}$ & $\begin{array}{c}-5.83 * * * \\
(1.53)\end{array}$ & $\begin{array}{c}-6.90^{* *} \\
(3.13)\end{array}$ \\
\hline $\log y$ & & $\begin{array}{l}0.18 \\
(.32)\end{array}$ & & & $\begin{array}{l}-0.31 \\
(.45)\end{array}$ & $\begin{array}{l}-0.61 \\
(-0.70)\end{array}$ \\
\hline Infant $\mathrm{M}$ & & & $\begin{array}{c}-0.014^{* *} \\
(.001)\end{array}$ & & $\begin{array}{c}-0.03^{* * *} \\
(.001)\end{array}$ & $\begin{array}{c}-0.03^{* *} \\
(0.01)\end{array}$ \\
\hline LogCal & & & & $\begin{array}{l}2.67^{*} \\
(1.40)\end{array}$ & $\begin{array}{c}0.94 \\
(1.44)\end{array}$ & $\begin{array}{l}1.45 \\
(2.38)\end{array}$ \\
\hline CER & & & & & $\begin{array}{l}0.03 \\
(.04)\end{array}$ & $\begin{array}{c}0.00 \\
(0.09)\end{array}$ \\
\hline VEG & & & & & $\begin{array}{c}0.10 \\
(0.06)\end{array}$ & $\begin{array}{c}0.09 \\
(0.13)\end{array}$ \\
\hline SUG & & & & & $\begin{array}{c}0.04 \\
(0.05)\end{array}$ & $\begin{array}{c}0.04 \\
(0.12)\end{array}$ \\
\hline MEAT & & & & & $\begin{array}{c}-0.18^{* *} \\
(0.07)\end{array}$ & $\begin{array}{r}-0.28^{*} \\
(0.16)\end{array}$ \\
\hline ROOT & & & & & $\begin{array}{l}0.01 \\
(.04)\end{array}$ & $\begin{array}{l}-0.01 \\
(0.01)\end{array}$ \\
\hline MILK & & & & & $\begin{array}{c}-0.21^{* * *} \\
(0.05)\end{array}$ & $\begin{array}{l}-0.20 \\
(0.12)\end{array}$ \\
\hline FRU & & & & & $\begin{array}{c}0.10 \\
(0.07)\end{array}$ & $\begin{array}{l}0.08 \\
(.14)\end{array}$ \\
\hline AFAT & & & & & $\begin{array}{l}-0.19 \\
(.21)\end{array}$ & $\begin{array}{l}-.27 \\
(0.43)\end{array}$ \\
\hline PUL & & & & & $\begin{array}{l}0.16^{*} \\
(0.08)\end{array}$ & $\begin{array}{l}0.03 \\
(.14)\end{array}$ \\
\hline Estimator & OLS & OLS & OLS & OLS & OLS & LAD \\
\hline $\mathrm{R}^{2}$ & 0.09 & 0.1 & 0.19 & 0.17 & 0.74 & \\
\hline $\mathrm{N}$ & 50 & 50 & 50 & 44 & 43 & 43 \\
\hline
\end{tabular}

Dependent variable: Log population density 2000. Notes: (a) The variables in the table are: Body size is measured by weight in $\mathrm{kg}$; log y is log PPP GDP per capita; Infant $\mathrm{M}$ is the mortality rate at birth; LogCal is calorie consumption per person per day. The remaining variables are dietary shares (in percent) of food consumption. See text for definitions. (b) All regression include a constant term. (c) ${ }^{* * *},{ }^{* *},{ }^{*}$ refer to significance at the 1, 5 and $10 \%$ level, respectively. (d) Standard deviations (in parenthesis) are robust to heteroscedasticity. (e) In the LAD regressions standard deviations are bootstrapped with 1000 repetitions.

As a final check of robustness we re-estimated the model from column 5 by running outlier robust median (LAD) regressions. The results are shown in column 6; body size continues to be significantly negatively correlated with population density.

Similar results are reported in Koepke and Baten, (2005a,b) using archaeological data on height. Their data is based on skeletal remains and pertain to Europe during the past two 
millennia. In order to examine the regional determinants of body size, Koepke and Baten provide regression results where population density (and a set of additional controls) is regressed on height; in all cases the coefficient for density is negative and appears economically significant, albeit the association is somewhat imprecisely estimated.

In sum, the evidence discussed above pertaining to human societies as well as non-human samples quite strongly suggest an operative quantity-quality trade-off between size and number of offspring. In the next section we provide a model which encompasses this fundamental tradeoff.

\section{A Bio-Economic Growth Theory}

We develop the model in a series of steps. First, Section 3.1 provides a brief introduction to the field of allometry, from which we draw an essential equation in pinning down subsistence consumption. Section 3.2 then explains how subsistence consumption is determined in the model, after which we turn to the intergenerational law of motion for body size in section 3.3. Finally, Section 3.4 and 3.5 discuss the preferences and optimization problem of the household and production, respectively.

\subsection{A Crash Course in Allometric Scaling and Energy Consumption. Allometric scal-}

ing is a technique used in biology to study how selected biological variables of an organism correlate with the size of the organism. A fundamental allometry is found between energy consumption $B$ and body mass $m$ of a mammal, and is known as "Kleiber's Law" (Kleiber, 1932):

$$
B=B_{0} \cdot m^{b}, \quad \text { with } b=3 / 4,
$$

where $B$ is the basal metabolic rate and $B_{0}$ is a species-dependent constant. ${ }^{16}$ Thus, drawn on log-log paper the energy-body mass relationship is linear with slope of 3/4, see Figure 4. A slope of $3 / 4$ has been verified by Brody (1945) for almost all terrestrial animals yielding the famous "mouse-to-elephant curve". ${ }^{17}$

\footnotetext{
16 "Metabolism" refers to the biochemical processes by which nutrients are transformed into energy, which allows the organs of the body (i.e. ultimately the cells of the body) to function. The "basal metabolic rate" is defined as the amount of energy expended while at rest.

${ }^{17}$ Admittedly, there still exists some debate about the exact magnitude of $b$. Yet it seems to be fair to say that the possible variance under discussion is trivialized in comparison with the precision of parameter estimates associated with "laws" in the social sciences. For example, Darveau et al., 2002, found exponents between 0.76 and 0.79 and around 0.82 for exercising animals.
} 
Figure 4: Kleiber's Law

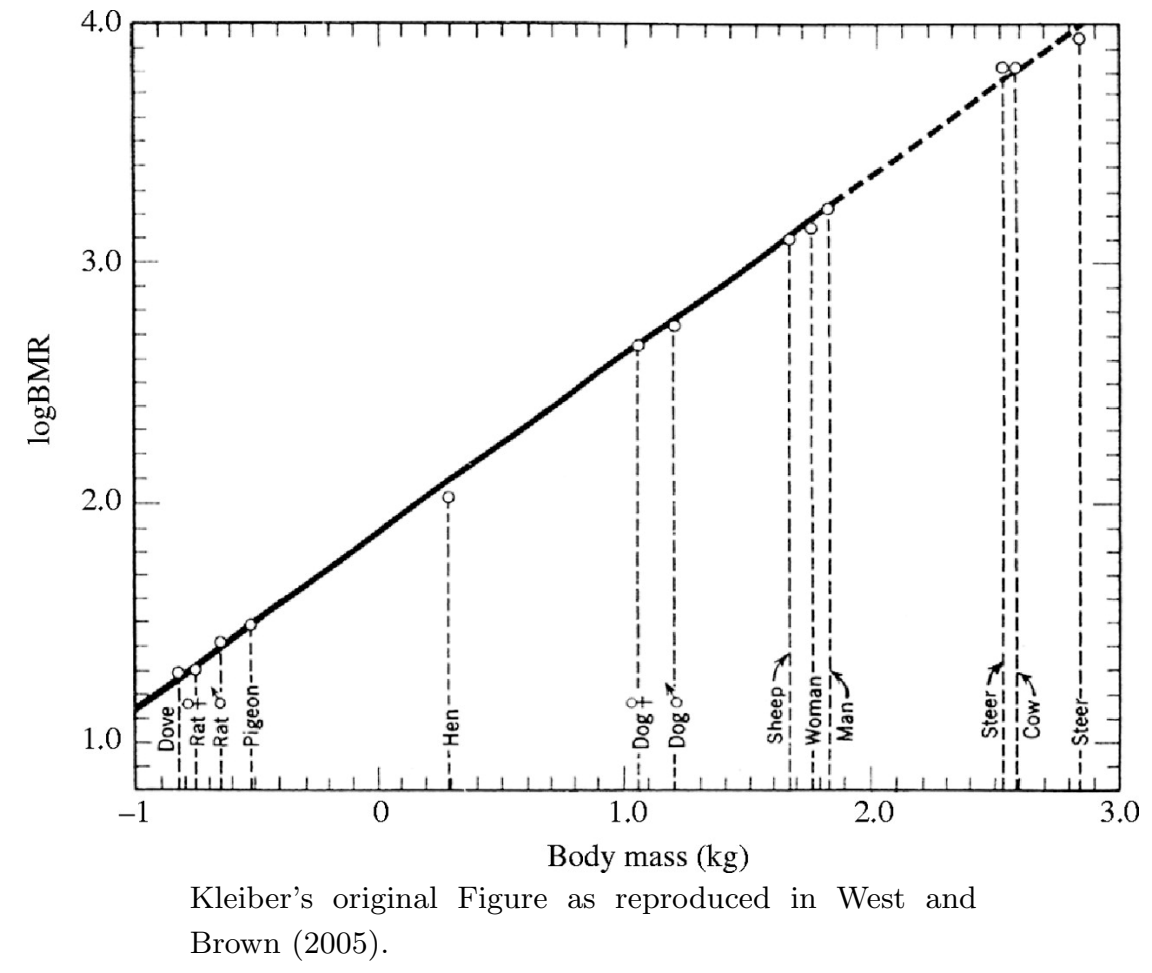

Biologists have long been puzzled by the $3 / 4$ finding because the prior would be $b=2 / 3$. To see why, note that an animal $x$ times as large as another in height is $x^{2}$ larger in terms of surface area, and $x^{3}$ larger in terms of volume, or mass $m$. Since energy use is proportional to heat loss, and heat exchanges through body surface, the metabolic rate should be proportional to $x^{2}$ which is itself proportional to $m^{2 / 3}$.

Recent research has revealed that the fallacy of this reasoning lies in its application of Euclidian geometry when fractal geometry is appropriate. The beauty of the new theory, first developed by West, Brown and Enquist (1997), lies in its foundations on first principles. This makes it very general, and in fact it has already been applied to a multitude of biological problems from "genomes to ecosystems" (West and Brown, 2005). Some of the applications and extensions, for example, those on fertility and mortality are especially relevant for economic analysis.

A living organism needs to feed its cells. For that purpose energy and material is transported through hierarchically branching networks like blood vessels in mammals. The network in use, however, is not of arbitrary structure. Given that organisms have evolved through natural selection, it must be one that minimizes energy used for transport i.e. one that minimizes 
hydrodynamic resistance. West et al. (1997) have shown that organisms that minimize energy dissipation fulfil Kleiber's law. A sketch of the proof can be found in Appendix B.

Ultimately, Kleiber's law conveys an important piece of information: Larger animals are more energy efficient. This is reflected in the fact that energy needs per unit of mass, $B / m$, is declining in body size ( $\mathrm{cf}(1))$. The theory of West et al. provides a deep foundation of this fact: energy dissipation per cell decreases with body mass. Thus, as an organism gets smaller each single cell is forced to work harder. This basic insight can explain a multitude of biological phenomena like, for example, why a mouse has a faster heartbeat, sleeps more, and have a shorter life span than an elephant. It also provides the deep determinant of some phenomena discussed by the economics profession like, for example, why human health and productivity are positively correlated with body size. ${ }^{18}$

3.2. Subsistence Consumption. We employ Kleiber's law in order to provide a bio-economic foundation of subsistence needs in an overlapping generations model with endogenous fertility. According to the OLG setup life is separated into two periods. First, childhood (after weaning), defined as the period of body growth and dependence on food provided by the parent. Second, adulthood, defined as the period of constant body size, work effort and (asexual) reproduction. We first consider the metabolic needs of adults.

The body size of an adult is predetermined by the individual's nutritional intake during childhood. Accordingly, we assume that the body size of an adult remains constant. ${ }^{19}$ Subsistence consumption is not completely predetermined, since it also depends on fertility. From the physiological literature we use the fact that rearing up a child from conception to weaning increases the mother's metabolic needs by a factor $\rho$, where $\rho \approx 0.2$ (Prentice and Whitehead, 1987; Sadurkis et al., 1988).

Denoting by $B_{t}$ energy used up by the mother's own body, and $n_{t}$ the number of children, total metabolic needs of an adult, $E_{t}$, is thus given by:

$$
E_{t}=\left(1+\rho \cdot n_{t}\right) \cdot B_{t}=\left(1+\rho \cdot n_{t}\right) \cdot B_{0} m_{t}^{b}
$$

\footnotetext{
${ }^{18}$ See Fogel (1994) for a discussion of the evidence on health, body size and productivity.

${ }^{19}$ From now on we refer to $m_{t}$ as body size rather than body mass. This is done for semantic reasons. The term "body size" is closer to the the literature in anthropology and economic history, which focusses on human height. It also avoids confusion with the body mass index.
} 
In (2) $E_{t}$ measures metabolic needs in terms of energy, expressed, for example, in kcal. per period. In order to convert energy into goods we introduce the energy exchange rate $\epsilon$, which is measured in kcal. per unit of a unique consumption good. While consumption expenditure is a control variable for parents, the energy extracted from a unit of consumption depends on the food staple available, which we treat (similar to technological progress) as exogenous. Later we will vary $\epsilon$ to investigate exogenous shifts in human diet, as would be caused, for example, by the introduction of the potato.

Employing the energy exchange rate we get subsistence consumption, i.e. the metabolic needs of an adult in terms of consumption goods, $\bar{c}_{t}=E_{t} / \epsilon$. Note that, in contrast to the existing literature in economics, subsistence consumption is not a constant but depends on the individual body size and fertility in adulthood. Subsistence consumption is thus generation-dependent and indexed by $t$.

3.3. The Intergenerational Law of Motion for Body Size. In order to establish the intergenerational link between body sizes we begin with a discrete time version of West, Brown, and Enquist's (2001) model of ontogenetic growth. ${ }^{20}$ Let $N_{t}$ denote the number of human cells in period $t, b_{c}$ the metabolic energy a cell requires during childhood for maintenance and replacement, and $e_{c}$ the energy required to create a new cell. Then metabolic needs during childhood are given by $E_{t}^{c}$ in (3).

$$
E_{t}^{c}=b_{c} N_{t}+e_{c}\left(N_{t+1}-N_{t}\right)
$$

Next we insert the fact that body mass of a child $m_{t}^{c}$ consists of the mass of a single cell $\bar{m}$ times the number of cells, i.e. $m_{t}^{c}=\bar{m} N_{t}$, and solve for the change in body mass. This gives a relationship between the size of a child after weaning $m_{t}^{c}$ and as a grown up. That is, the size of next generation's adult $m_{t+1}$ is:

$$
m_{t+1}=\frac{\bar{m}}{e_{c}} E_{t}^{c}+\left(1-\frac{b_{c}}{e_{c}}\right) m_{t}^{c}
$$

Next, we use from the science of life history the fact that a child after weaning equals $\mu$ times the size of the mother (Charnov, 1991, 1993), so $m_{t}^{c}=\mu m_{t}$. This provides a simple mapping of body size across generations. Finally, denote by $c_{t}$ the consumption of a child, to be determined below from optimization. Then total energy intake during childhood is $c_{t} \cdot \epsilon=E_{t}^{c}$. Inserting

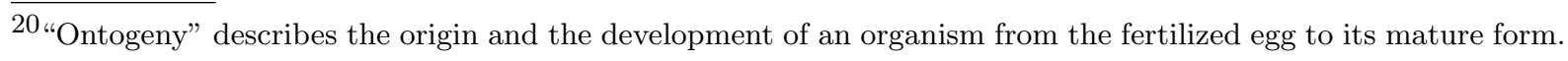


this into (4) leaves us with a law of motion for body size across generations:

$$
m_{t+1}=a \cdot \epsilon \cdot c_{t}+(1-d) \cdot \mu \cdot m_{t}
$$

where $a \equiv \bar{m} / e_{c}$ and $d \equiv b_{c} / e_{c}$. For future reference, note that $d$ and $a$ can be viewed as deep physiological parameters, which may exhibit some variation across humans due to natural selection. That is, due to processes whereby large or small body sizes were selected depending on e.g. climate related circumstances.

3.4. Individual's Optimization. A parent maximizes utility derived from child quality and quantity where quality is in the Beckerian (1960) sense measured by expenditure for consumption (i.e. nutrition) per child, $c_{t}$. For simplicity we impose a logarithmic form for the utility function:

$$
U\left(c_{t}, n_{t}\right)=\log \left(c_{t}\right)+\gamma \log \left(n_{t}\right)
$$

with $\gamma$ denoting the weight of child quantity in utility.

These preferences can be given an evolutionary motivation. Suppose nature maximizes genetic fitness, given by the total number of descendants produced. Denote by $\pi_{t}$ the fraction of surviving children. Then genetic fitness of the current generation is given by $\prod_{t=0}^{\infty} \pi_{t} n_{t}$. As the solution of the maximization problem is invariant to a monotonous transformation of the objective function, we let nature maximize the logarithm of genetic fitness so that the objective becomes $\max \sum_{t=0}^{\infty} \log \pi_{t}+\sum_{t=0}^{\infty} \log n_{t}$. From the allometric literature we know that longevity (survival probability) of free living animals scales with body mass at factor $1 / 4$ (Brown et al., 2004), i.e. $\pi_{t} \propto m_{t}^{\psi}, \psi=1 / 4$. Evaluating (5) at the steady-state, we find that $m_{t} \propto c_{t}$ and thus $\log \pi_{t} \propto \psi \cdot \log c_{t}$. Inserting this information into "nature's objective function" and dividing through by $\psi$, we find that maximizing genetic fitness is tantamount to maximizing $\sum_{t=0}^{\infty}\left[\log \left(c_{t}\right)+(1 / \psi) \cdot \log \left(n_{t}\right)\right]$. This is fulfilled when mother's of each generation maximize (6) and $\gamma$ equals $1 / \psi$. Note that evolutionary considerations thus predict $\gamma \approx 4$, provding a deep foundation of the utility weight of child quantity.

Total child expenditure is constrained by parental income and subsistence consumption of the parent. Furthermore we assume that each parent is endowed with one unit of time and rearing a child requires a certain fraction $\tau$ of parental time. Let $y_{t}$ denote potential income such that available income of a family is $y_{t}\left(1-\tau \cdot n_{t}\right)$. Combining the budget constraint with energy 
requirements (2) and applying the energy exchange rate leads to a single constraint:

$$
y_{t}\left(1-\tau \cdot n_{t}\right)-c_{t} n_{t}-\left(1+\rho n_{t}\right) B_{o} m_{t}^{b} / \epsilon=0
$$

Note that we do not require $\tau>0$. The assumption of time intensive child rearing is made to add more realism and to better relate the model to the literature on the standard quantity-quality trade-off. All our all main results would go through without a temporal trade off for parental time (i.e. for $\tau=0$ ) due to the presence of the biological trade-off originating from the fact that larger mothers need more energy to sustain their own body.

Parents maximize (6) s.t. (7), by choosing fertility $n_{t}$ and nutritional expenditure per child $c_{t}$. From the first order conditions we obtain optimal child quality and quantity:

$$
\begin{aligned}
c_{t} & =\frac{\rho\left(B_{0} / \epsilon\right) m_{t}^{b}+\tau y_{t}}{\gamma-1} \\
n_{t} & =\frac{(\gamma-1)\left[y_{t}-\left(B_{0} / \epsilon\right) m_{t}^{b}\right]}{\gamma \rho\left(B_{0} / \epsilon\right) m_{t}^{b}+\gamma \tau y_{t}} .
\end{aligned}
$$

Observe that $\partial n_{t} / \partial m_{t}<0$ and $\partial c_{t} / \partial m_{t}>0$. Higher metabolic needs of fertility induce larger mothers to prefer to have less children and to nourish them better. Observe furthermore that $\partial n_{t} / \partial y_{t}>0$ and $\partial c_{t} / \partial y_{t}>0$. With higher income mothers prefer to have more children and to nourish them better implying that the quantity-quality trade off is driven by metabolic needs and not by income.

3.5. Production and Demographics. It is worth observing that the model so far has involved elements that are reasonable (subject to variation in parameter values perhaps) for any mammalian species. However, humans naturally differ in their ability to modify their environment. The most basic manifestation of this ability lies in the assumption that humans can operate a production technology. Specifically, we assume that total income, $Y$, is determined at the macro-level by a body size adjusted technology:

$$
Y_{t}=A m_{t}^{\phi} L_{t}^{\alpha} X^{1-\alpha}=y_{t} \cdot L_{t}, \quad \phi \in(0,1-\alpha), \alpha \in(0,1) .
$$

The parameter $\phi$ quantifies the return to body size. As usual $A$ captures technological knowledge, $L_{t}$ denotes population size in period $t$ and $X$ is land. Since land is assumed to be constant (and $1-\alpha>\phi)$ the technology implies stagnation in the long-run at an equilibrium population density $L / X$ unless general productivity $A$ is growing without bound. In terms of size, the parameter in 
Kleiber's law reasonably fulfills: $b>\phi$, as $b=3 / 4$. This parameter constellation will be useful below.

In other species, beyond humans, a more appropriate benchmark could be to think of total "income" as simply given by quality adjusted land; that is, $Y=A \cdot X$. Accordingly, resources per capita would decline as the species in question becomes more abundant. Observe that we can capture this case by putting $\alpha=\phi=0$ in the production function above. Of course, some primates (beyond humans) are able to work in groups and employ tools in the context of food procurement. This could be seen as a manifestation of a (primitive) sort of production function. More generally, then, one could think of the production function as being species dependent, with $\alpha, \phi$ and $A$ varying. However, it should be uncontroversial to assert that only human populations are able to produce technological progress, as would be captured in a rising level of A.

Finally, population evolves according to

$$
L_{t+1}=n_{t} L_{t},
$$

where $n_{t}$ is given by equation $(8 \mathrm{~b})$.

With equations (1) to (10) our bioeconomic model of population size and body size is complete.

\section{Steady State Equilibrium and Comparative Statics}

4.1. Steady-state. At a steady-state equilibrium we observe $n^{*}=1$ and thus from $(8 \mathrm{~b})$

$$
y^{*}=\frac{(\gamma \rho+\gamma-1) B_{0}}{(\gamma-1-\gamma \tau) \epsilon} \cdot\left(m^{*}\right)^{b}
$$

In order to examine the stability properties of the model, we construct a phase diagram in $\left(m_{t}, L_{t}\right)$-space. We begin by substituting energy consumption per child (8a) into the law of motion for body size (5) and fertility (8b) into the law of motion for population size (10). This renders the two-dimensional dynamic system (12), with $y_{t}$ determined by (9).

$$
\begin{aligned}
m_{t+1} & =\frac{a \epsilon}{\gamma-1}\left[\rho\left(B_{0} / \epsilon\right) m_{t}^{b}+\tau y_{t}\right]+(1-d) \mu m_{t} \\
L_{t+1} & =\frac{(\gamma-1)\left[y_{t}-\left(B_{0} / \epsilon\right) m_{t}^{b}\right]}{\gamma \rho\left(B_{0} / \epsilon\right) m_{t}^{b}-e y_{t}} \cdot L_{t} .
\end{aligned}
$$


Inserting (9) provides the isocline along which body size remains constant, $\Delta m=m_{t+1}-m_{t}=0$, implicitly given by

$$
G\left(m_{t}, L_{t}\right)=[1-(1-d) \mu] \frac{\gamma-1}{a \epsilon}-\rho \frac{B_{0}}{\epsilon} m_{t}^{b-1}-\tau A m_{t}^{\phi-1} L_{t}^{\alpha-1}=0
$$

Implicitly differentiating we obtain $\mathrm{d} L_{t} / \mathrm{d} m_{t}<0$; the $\Delta m=0$-isocline is negatively sloped. Observe that $\Delta L<0$ when $L_{t}$ lies above the isocline and $\Delta L>0$ when $L_{t}$ lies below. Moreover, observe that $L_{t} \rightarrow 0$ for $m_{t} \rightarrow \infty$ and $L_{t} \rightarrow \infty$ for $m_{t} \rightarrow \bar{m}>0$.

Using (11) and (9) we obtain population density as a function of body stature.

$$
\left(\frac{L_{t}}{X}\right)=\left[\frac{A \epsilon(\gamma-1-\gamma \tau)}{(\gamma \rho+\gamma-1) B_{0}}\right]^{1 /(1-\alpha)} \cdot m_{t}^{\frac{\phi-b}{1-\alpha}} .
$$

Since land area is constant, equation (14) provides the $\Delta L=0$-isocline in $\left(m_{t}, L_{t}\right)$-space. As $b>\phi$, the isocline is a hyperbola with $L_{t} \rightarrow 0$ for $m_{t} \rightarrow \infty$ and $L_{t} \rightarrow \infty$ for $m_{t} \rightarrow 0$. Recall that for the $\Delta m=0$-isocline $L_{t} \rightarrow \infty$ for $m_{t} \rightarrow \bar{m}>0$. Hence, there is a unique intersection between the $\Delta L=0$ and $\Delta m=0$-isoclines. Finally, observe $\Delta m_{t}<0$ to the right of the $\Delta m=0$-isocline and $\Delta m_{t}>0$ to the left. Figure 5 summarizes the discussion in a phase diagram.

Figure 5: Phase Diagram

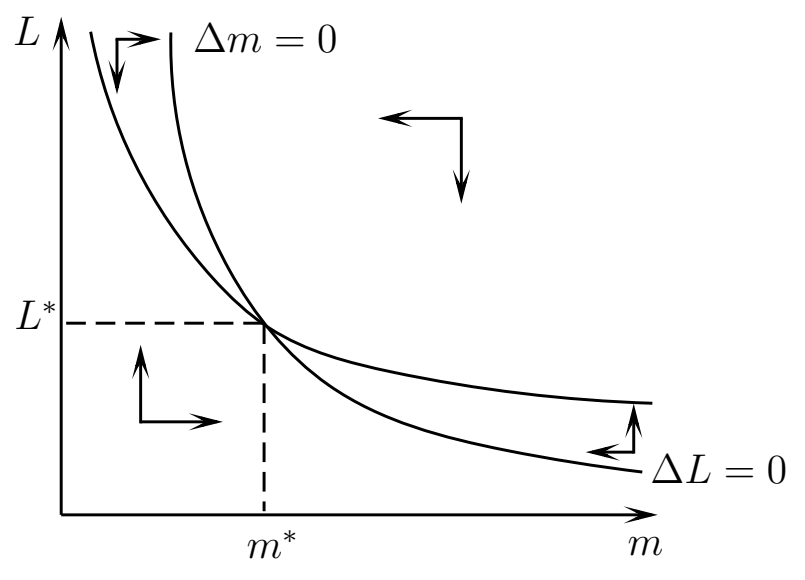

We can solve explicitly for the steady-state. Inserting (11) into (12b) (evaluated at $\Delta m_{t}=0$ ) provides equilibrium body size. Equilibrium population size can then be inferred from (14). 
Proposition 1. Existence of a steady-state equilibrium. There exists a unique bioeconomic steady-state equilibrium $\left(m^{*}, L^{*}\right)$ at

$$
\begin{aligned}
m^{*} & =\left\{\frac{a B_{0}}{(\gamma-1)[1-(1-\alpha) \mu]}\left[\rho+\frac{\tau(\gamma \rho+\gamma-1)}{\gamma-1-\gamma \tau}\right]\right\}^{1 /(1-b)} \\
\left(\frac{L^{*}}{X}\right) & =\left[\frac{A \epsilon(\gamma-1-\gamma \tau)}{(\gamma \rho+\gamma-1) B_{0}}\right]^{1 /(1-\alpha)} \cdot\left(m^{*}\right)^{\frac{\phi-b}{1-\alpha}}
\end{aligned}
$$

The arrows of motion in Figure 5 suggest that the steady-state is a globally stable spiral. Since time is discrete, however, a second possibility arises, since there maybe overshooting and explosive behavior (Galor, 2007). In Appendix C we evaluate stability numerically and show that the equilibrium is indeed stable when model parameters are selected from empirically plausible ranges.

Since $b>\phi$ (cf. Section 3.5), inspection of the equilibrium provides the following general conclusion:

Proposition 2. Damuth's law. In steady-state equilibrium there is a negative association between population size and body size. Humans of larger stature live in less densely populated areas.

As explained in Section 2, the over-all allometric equation estimated by Damuth is that $L / X=$ constant $\cdot m^{-3 / 4}$. However, there is considerable variation in the slope and position of the allometry between size and density across different species. The present theory provides an interpretation of this variation.

First, under the present theory the constant term encompasses $A$ and $\epsilon$, which quite naturally would vary across species and geo-zones. The general prediction is that species living in "richer" environments (high $A$ or $\epsilon$ ) should be able to sustain a larger density, for given (average) body size.

Second, the slope of the allometry is also predicted to be species dependent, since production function parameters show up in the scaling law. As argued above it seems reasonable to assume that the ability to invoke a production function in food procurement is species dependent. In general the model would predict an allometry of the form $L / X=$ constant $\cdot m^{(\phi-b) /(1-\alpha)}$. An interesting special case is where there is no production function in the sense that the species under consideration has a total "endowment" of food, which is proportional to the area it occupies: $Y=A \cdot X$. In this case the allometry becomes $L / X=$ constant $\cdot m^{-b}$. As, by Kleiber's 
law, $b=3 / 4$ this is exactly consistent with Damuth's "average" finding across a large number of different species. In general, however, the numerical size of the exponent may exceed or fall short of 3/4 depending on the exact size of $\phi$ and $\alpha$. Specifically, the slope is numerically smaller if $\phi / \alpha>b$. That is, if the influence of body size on per capita output is sufficiently large relative to the influence of body size on per capita subsistence needs. ${ }^{21}$

Next, inspect (11) to conclude

PROPOSITION 3. Income per capita and body size. In the bioeconomic steady-state equilibrium there exists a positive association between body size and income per capita. Societies with larger citizens are richer.

The model therefore predicts a positive correlation between body size and income per capita, in keeping with the empirical evidence (e.g., Steckel, 1983; Brinkman et al., 1988).

4.2. Comparative statics. Observe that technology $A$ enters the equation for $L^{*}$ but does not matter for $m^{*}$. In combination with (11) this leads to the following conclusion:

Proposition 4. Technological innovations. A discrete increase in productivity (A) leads to a more densely populated area but leaves equilibrium body size and income per capita unaffected.

In the model, a temporary increase in productivity will lead to temporary increases in nutrition and fertility. However, due to the biological feed-back loop from subsistence, nutritional expenditures per child will be lower (and so will be fertility) in the following generation. This process will continue until $n=1$ once again. At this point the temporary gain in body size has fully eroded, and the only result from the innovation is a larger population size. In the long run income per capita does not change since the larger population fully offsets the increase in $A$. Note also that similar results can be derived for alternative parameter changes associated with technology improvement. Lower dependence on limited land (larger $\alpha$ ) and higher efficiency in using brawn (increasing $\phi$ ) both lead to a higher population density without an equilibrium effect on body size and - according to (11) - on income.

${ }^{21}$ In order to fascilitate this interpretation, note that per capita income can be re-written: $y=A^{\frac{1}{\alpha}} x^{\frac{1-\alpha}{\alpha}} m^{\frac{\phi}{\alpha}}$, where $y$ is per capita output and $x$ is land per unit of output. Hence, in steady state, where $x$ is constant, the elasticity of income per capita with respect to $m$ is $\phi / \alpha$. 
As noted in the Introduction, there is convincing evidence testifying to the fact that technological change did increase population density in the aggregate, in pre-industrial times (e.g., Ashraf and Galor, 2008; Kremer, 1993). However, the lack of a long-run time trend during the last two millennia as a whole, in terms of body size, has also been established (Kunitz, 1987; Koepke and Baten, 2005a). The present theory thereby suggests that these potentially conflicting observations are in fact reconcilable.

At the same time we reiterate that these steady-state results do not preclude a positive shortrun impact of productivity gains on income and stature. Comparative dynamics will be discussed in the next section.

Next we turn to dietary innovations. One might expect that human stature would depend on the type of food consumed via the energy exchange rate $(\epsilon)$. That is, via the nutritional content of the food staple that people are subsiding on. In the present model we can examine the consequence for population density and body size of a change in the energy content of food, by varying $\epsilon$. Interestingly, inspection of (15) and (11) reveals the following.

Proposition 5. Dietary innovations. A higher energy exchange rate $(\epsilon)$, leads to higher population density, but leaves body size unaltered. Steady state income falls.

The chain of effects is as follows. When $\epsilon$ rises, people of the next generation become larger and thus more productive. With higher income they expand their family, and population grows temporarily. With the population growing, however, productivity is decreasing. The productivity loss increasingly circumvents the initial efficiency gain through the energy exchange rate. In the long-run the demo-economy stabilizes at a constant population and lower income. A lower level of income resulting from the production side is nevertheless sufficient to support a larger population because of the improved energy exchange rate. In other words, the standard of living in terms of calories consumed - and thus body size - is the same as at the initial state before the change in diet. Yet population size is higher and income is lower than before.

In a recent study Nunn and Qian (2008) examine the impact on population size from the diffusion of the potato, which held distinct dietary benefits compared with existing food staples. Their estimates reveal a significant impact on population size. At the same time, the lack of any time trend in the average height of Europeans suggest this innovation had no impact of body size, as the proposed theory would suggest as a matter of steady-state prediction.

Taking the derivative of (15) with respect to $\tau$ provides the following result. 
Proposition 6. Organizational innovations. A decrease of time costs $(\tau)$ for child rearing leads to higher population density, smaller stature, and lower potential income.

It seems plausible that life as a hunter-gatherer involved a sharper distinction between "work" and "child rearing" than settled agriculture. Bringing children along hunting seems more problematic than bringing them along into the fields, for example. Hence, one might hypothesize that the onset of the Neolithic revolution brought with it an organizational innovation in child rearing; time cost per child went down. That is, the amount of time the child requires the adult to be away from production fell. Observe that this interpretation is consistent with the observation that work hours went up in the aftermath of the Neolithic revolution (Weisdorf, 2005); in steady-state, a reduction in $\tau$ is equivalent with an increase in work hours in production. If so, then the model predicts that the average body size in the population should shrink and population density rise, as seems to have happened (Clark, 2007; Weisdorf, 2005). ${ }^{22}$

Moreover, note that this result is robust to a more detailed modeling of a Neolithic revolution including technological innovations $(\phi, \alpha, A)$. As shown above, productivity improvements will only serve to increase population density, but will not affect body size.

Finally, observe from (11) that a reduction in $\tau$ has an ambiguous effect on actual income per capita. On the one hand people work more "in the fields", on the other hand there is a negative impact on productivity from rising population density.

Before we turn to comparative dynamics, we state the final comparative static result.

Proposition 7. Biological innovations. In areas where humans are selected to be larger (smaller d or larger a) income per capita is larger, and population density lower.

Physical anthropologists and biologists argue that some of the observed differences in human body size, across regions and countries, may be attributed to selection. According to Bergman's rule the body size of mammals tend to rise, as one moves away from the equator. The leading theory on the topic is that Bergman's rule is the result of selective pressures (e.g., Ruff, 2002). There are two parts to the argument. First, there is the geographic observation that as one moves away from the equator the temperature drops, which makes it more challenging to keep warm. Second, there is the geometric observation that as body size goes up the surface to

\footnotetext{
${ }^{22}$ A complementary reason for a drop in $\tau$ could involve learning, as distinct from organization. One might imagine that life as a farmer involves more routine work than life as a hunter-gatherer. Consequently, the time investment required to teach a child what it needs to know in order to survive as a hunter-gatherer may well have been larger. This would also suggest a larger $\tau$ in hunter-gatherer societies.
} 
volume ratio declines, which limits the extent of heat loss per unit of body mass. Since limited heat loss is an advantage in cooler climates, selection may have favored larger bodies in cooler areas. $^{23}$

If indeed such genetic differences have emerged in human societies they may be (crudely) captured by $a$ and $d$ in our model. For instance, a larger $d$ would be consistent with higher energy costs for cell maintenance and replacement, which would imply smaller asymptotic body size. ${ }^{24}$ The model predicts that in areas where $d$ is larger population density will be higher, and, due to diminishing return to labor input, income per capita will be lower. If true, then income per capita may have differed across regions in Malthusian times; being larger in places with larger individuals. Note, however, that this would not mean that living standards would necessarily differ, since larger bodies have greater subsistence needs.

\section{Comparative Dynamics}

5.1. Parameter values. In order to simulate the model and study the implied dynamics we proceed with a calibration of the model. We start with the biological components. We put $B_{0}=70$ and $b=0.75$ according to Kleiber's (1932) law. Following Prentice and Whitehead (1987) we set $\rho=0.2$ implying that a woman who is pregnant with one child must consume 1.2 times the energy of a non-pregnant woman. According to WHO (2006) a grown up American female weighs on average $m=59 \mathrm{~kg}$. Child weight after weaning is $9 \mathrm{~kg}$ implying $\mu=0.15$. For calibration of $d$, the amount of energy used for cell maintenance relative to cell creation, we turn to West et al.'s (2001) model on ontogenetic growth in continuous time, and investigate the human growth process. For that purpose we use standardized weight-for-age curves for US females as provided by the WHO. We take data points in $\mathrm{kg}$ for body mass at the age of fourteen $\left(m_{v}=50\right.$ for $\left.v=14\right)$ and for grown up females $\left(m_{s}=59\right)$. This yields the estimate $d=0.63{ }^{25}$

We set the fraction of parental time spend on child rearing $\tau$ to 0.1 , thereby implicitly assuming that it takes two years to rear a child. This parameter value is a compromise. On the one hand, it overestimates the value of child care in the home caused by pre-schoolers for modern societies

\footnotetext{
${ }^{23}$ Note that since temperature also drops with altitude a height gradient may also be found in terms of elevation. ${ }^{24}$ At a deeper level one may think of the parameters $b_{c}$ and $e_{c}$ in equation (3) as implicitly capturing heat loss. Less heat loss implies that fewer calories to maintain the cells of the body are needed; this would be consistent with a lower value for $b_{c}$, which in turn means a smaller parameter value for $d$.

${ }^{25}$ The continuous time ontogenetic growth equation is given by $\dot{m}=\delta m^{b}+d m$, where $d$ is the energy used for cell maintenance relative to cell creation (West et al. , 2001). From that we obtain $d=$ $-\log \left(\left[1-\left(m_{v} / m_{s}\right)^{1 / 4}\right] /\left[1-\left(m_{0} / m_{s}\right)^{1 / 4}\right]\right) \cdot 4 / v$
} 
(estimated to be between 1.5 and 2.8 percent of GDP for Sweden; Gustafsson and Kjulin, 1994). On the other hand, together with our other parameter estimates it implies that a traditional couple (one breadwinner) with 2 children uses 17 percent of their income for child expenditure and spend 36 percent of potential income (including opportunity costs) on their children. These figures underestimates child expenditure of such a couple in today's Australia (where the figures are between 23 and 34 and between 49 and 54 percent, respectively; see Apps and Rees, 2002).

Because $56 \mathrm{~kg}$ is the mean female weight in our sample of less developed countries (Table 1) we set the remaining bioeconomic parameter $a$ such that $m^{*}=56$. Since we are investigating subsistence economies we have deliberately set $m^{*}<m_{s}$ to allow for the possibility of a permanent ontogenetic growth spurt along with industrialization and perpetual economic growth. This provides the estimate $a=0.32$

For the economic part of the model we set $\alpha=0.65$ according to Clark's (2007) estimates. We draw on Weil (2007) to approximate $\phi=0.025$. We set $\gamma=4$ in keeping with the evolutionary argument behind the utility function. To get at $\epsilon$ we do the following. Suppose equilibrium income is 400 (international Dollars) per year. In that case, during the period of adulthood measured by the length of the fecundity period (assumed as 20 years), equilibrium income is $\$ 8000$. These values pin down $\epsilon$ to 0.26 . We have one further parameter, $A$, which could be used to calibrate a particular equilibrium population size (or density). Yet, we found it more informative to report population density as relative deviation from stationary population (and thus normalized $A=1000$ ). Parameters and steady-state values are summarized in Table 2 .

TABle 2: Parameters of the Bio-Economy

\begin{tabular}{cccccc}
\hline \hline$a$ & $b$ & $d$ & $\mu$ & $\rho$ & $\epsilon$ \\
0.32 & 0.75 & 0.63 & 0.15 & 0.2 & 0.26 \\
\hline$\tau$ & $\alpha$ & $\phi$ & $m^{*}$ & $y^{*}$ & $A$ \\
0.1 & 0.65 & 0.025 & 56 & 400 & 1000 \\
\hline \hline
\end{tabular}

5.2. Experiments: Dynamic Properties of the Model. Our first numerical experiment is a permanent rise of productivity $A$ by 10 percent. This could have been the result of introducing a new agricultural technique (e.g. fertilizer), or a shock to climate (e.g. the end of the little ice age). Adjustment dynamics are qualitatively identical for a permanent rise of the energy exchange rate $\epsilon$, which could arise due to the cultivation or import of a new crop. In the phase 
diagram the parameter change leads to an upward shift of both the $\Delta m=0$-locus and the $\Delta L=0$-locus leaving the intersection at $m^{*}$ unchanged. As a consequence the bioeconomic system leaves the initial equilibrium in north eastern direction. People react on the improved conditions by having more kids and nourishing them better. Adjustment dynamics shown in Figure 6 set in.

Figure 6: Adjustment Dynamics after Permanent Technology Shock
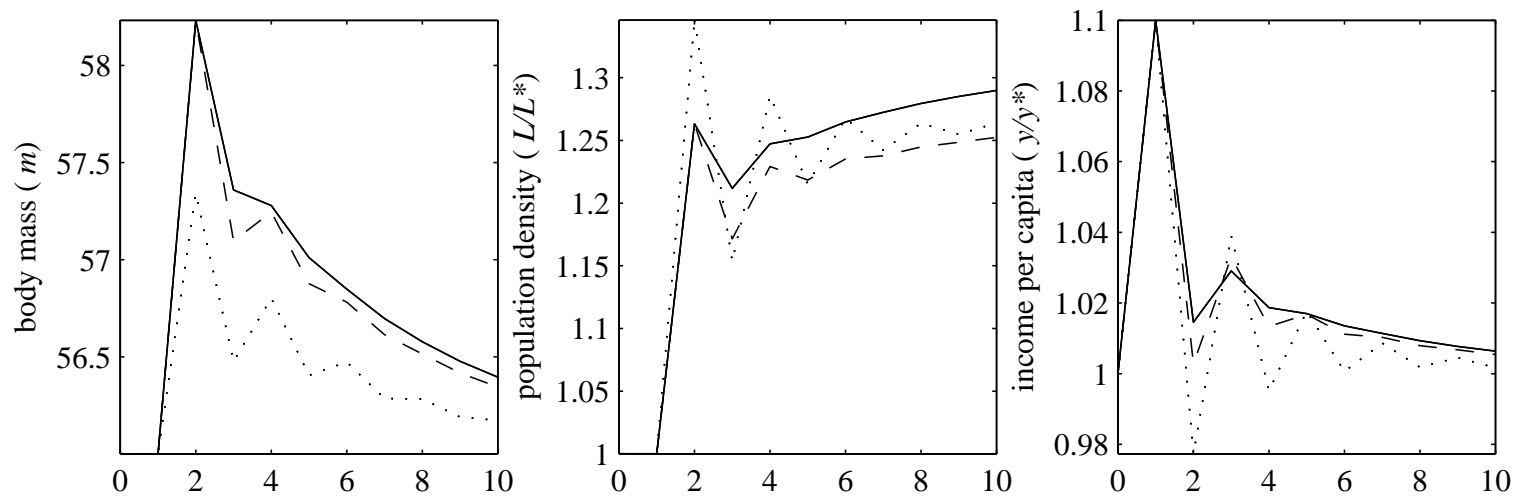

Parameters from Table 2 (solid lines); and $\alpha=0.6$ (dashed lines) and $\tau=0.05$ (dotted lines). Population density and income are measured relative to initial steady-state. The $x$ axis measures time in generations after the shock.

Solid lines in Figure 6 show the resulting adjustment dynamics for benchmark parameters. Robustness checks have shown that the bioeconomic system reacts most sensitive to value changes of parameters $b, \alpha$, and $\tau$. Since $b$ is fixed by nature, we provide sensitivity analysis with respect to $\alpha$ (dashed lines) and $\tau$ (dotted lines).

Higher productivity (or an increase in the energy exchange rate) leads to a temporary rise in body size and a permanent rise of population size (and density) where the importance of land in production and child rearing time determine the oscillatory behavior along the adjustment path. Generally, however, the second generation born after the shock is too large with respect to both population size and body size. Productivity is relatively low and parents reduce fertility and investment in child quality, both of which remain nevertheless above pre-shock level. As a consequence of lower population density, income of the third generation is a little higher than income of the second generation and the bioeconomic system adjusts in damped oscillations 
towards its initial equilibrium of income and body mass. Since fertility, however, along the transition stayed above steady-state level, population density at the new equilibrium is permanently higher.

These patterns, with respect to population and body size dynamics, are rather similar to what is found in the data. The long-run evolution of population trends are fairly familiar to historians and economists working on growth in the long run. Briefly, up until somewhere in the 19th century population growth was slow in Western European countries. Accordingly, for most of the preceding millennia, prior to the onset of the industrial revolution, the growth trajectory is slightly upward sloping, with occasional disruptions, for example, those caused by the Black Death (e.g., Galor, 2006).

At a finer level, however, existing evidence reveals that population growth followed an oscillatory trajectory, much like what we see in Figure 6. The population oscillations are found empirically at the level of parishes in rural England (Duncan et al., 2001), as well as on the macro level (Galloway, 1986; Lee and Loschky, 1987); the cyclicality appears to be a pervasive phenomenon.

Figure 7, drawing on data compiled by Kunitz (1987), show the evolution of height in England over roughly 2 millennia. The data should be interpreted with care, as they draw on a variety of archaeological excavations, which may not be equally representative. Moreover, in later periods the data is historical and refers to average size of army recruits. In addition, the time intervals are somewhat irregular. Nevertheless, the general impression is one of oscillations around a roughly constant trend level of height $($ circa $170 \mathrm{~cm})$.

The careful study by Koepke and Baten (2005a), which also draws on height data derived from skeletal remains, find strong evidence in favor of oscillations in body size around a constant trend, during the last two millennia in Europe as a whole. The sample size is much larger in Koepke and Baten's study than that implicit in Figure 7, and statistical tests reveal that the deviations from trend are significant.

Komlos and Baten (2004) discuss evidence on body size deriving from historical sources; their analysis draws on data stemming from army recruits from various regions. This evidence broadly follows similar regularities compared with the data stemming from skeletons, albeit the period in question is much shorter (18th and 19th century). Woitek (2003) provides rigorous time series tests, documenting fluctuations in body size for Americans and Europeans (army 


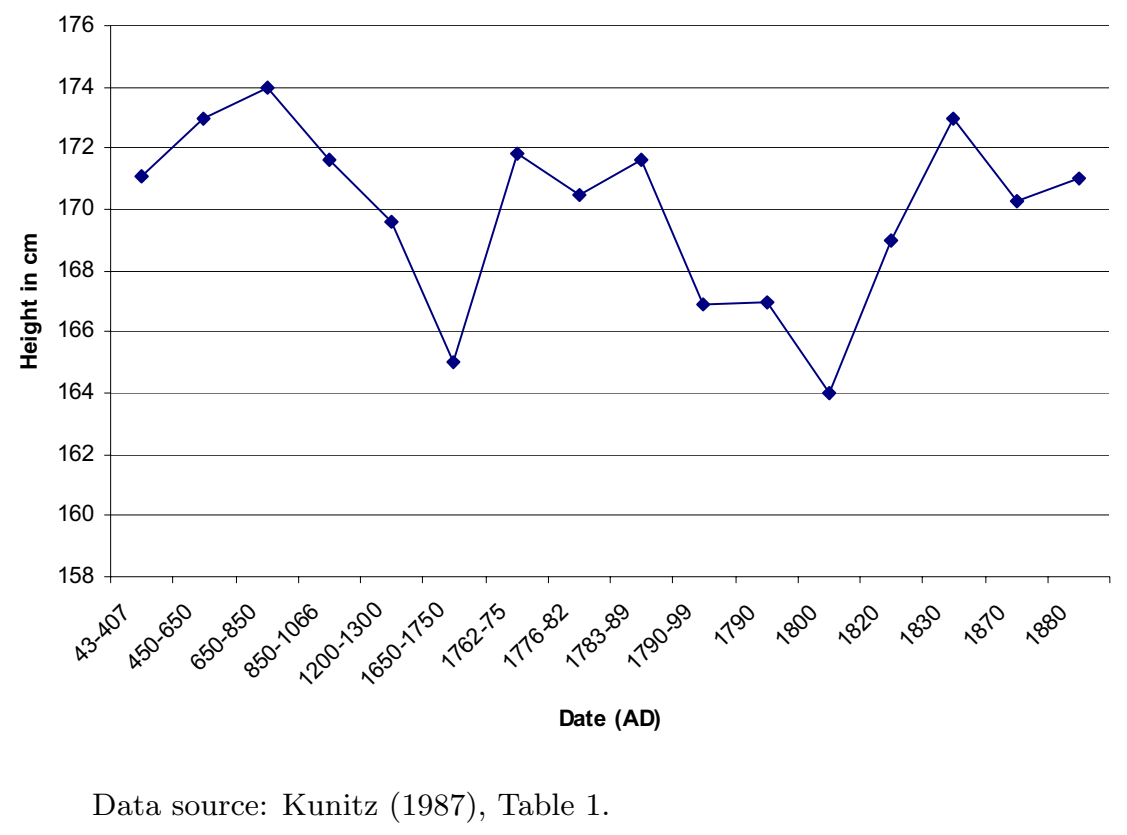

recruits) during the 18th and 19th centuries; Woitek detects cycles of 7-10 year duration, as well as cycles of higher frequency.

Taken together this evidence suggests that prior to the industrial revolution human societies witnessed step-wise increases in population (punctuated by occasional declines), while at the same time height exhibited very little trend in either direction (see also Clark, 2007). Instead, cyclical movements in height, around a constant trend, seem to have been the norm, in the very long-run. Cyclical adjustment to trend has also been the norm for population. These patterns are qualitatively consistent with the simulations shown in Figure 6.

However, at a more detailed level the data series for height, as depicted in Figure 7, exhibits considerable persistence while population was growing at a low but positive rate during the middle ages.

To capture these phenomena with a simulation of our model we conduct a business-cycle-cumgrowth experiment by introducing discretionary productivity shocks. Specifically we assume that $A_{t+1}=A_{t}$ with probability $0.85, A_{t+1}=1.02 \cdot A_{t}$, i.e. a positive productivity shock with probability 0.15 , and $A_{t+1}=0.92 \cdot A_{t}$, i.e. crop failure or technological regress (Aiyar et al., 2008), with probability 0.15. After simulating we have transformed the scale of variables for better comparison with the empirical time series. In particular, we converted body mass (i.e. weight) to height using a constant body mass index such that average height is $1.57 \mathrm{~m}$, i.e. 
the average height of females in our sample of less developed economies (cf Section 2); and we converted time from generations to years using the length of the fecundity period (20 years). The initial population density is normalized to one.

Figure 8: Female Body Size and Population Size from Year 0 to Year 1800
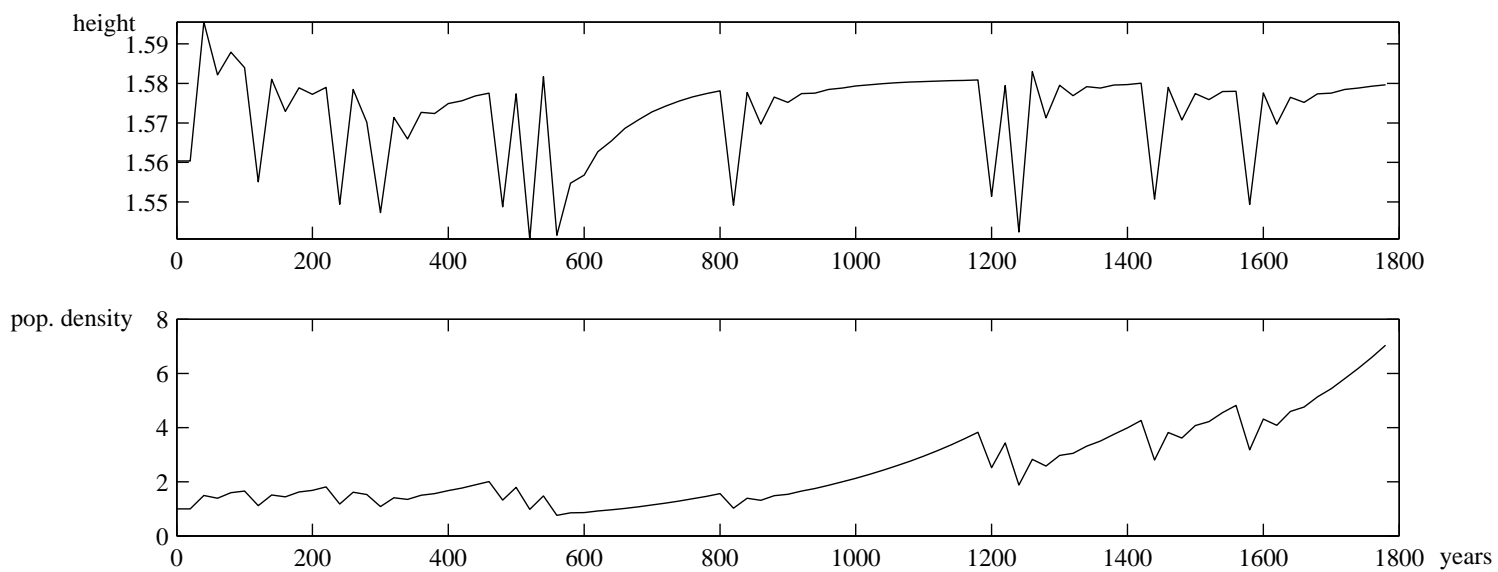

Parameters as for Figure 5. Productivity shocks as explained in the text. Conversion of time from generation to years using the fecundity period and of body size from weight to height using the body mass index

Figure 8 shows an example of a trajectory for our benchmark economy from Table 2. We simulated the economy for 90 generations, which yields the demo-metabolic history of a society from year 0 to year 1800 . The result corresponds quite well with the actually observed history. That is, the trajectories display long periods of smooth development, interrupted by abrupt changes and cyclical recovery. During the period under investigation population size has approximately increased sixfold (in accordance with the empirical facts, Kremer, 1993). At the same time there are cyclical fluctuations but no visible positive trend of body size.

Finally, observe that body size goes up after positive shocks and down after negative ones and returns to its long-run equilibrium afterwards. In Figure 6 we also see that body mass tracks prosperity in the short-run; its time series follows income per capita with a lag of one generation. Accordingly, the theory indicates that height can be used as a short run indicator for income per capita, as is commonly done by anthropologists and economic historians. In the longer run, however, positive productivity shocks have not manifested themselves in - on average - rising body size. 


\section{Conclusion}

The present paper has developed the first bio-economic general-equilibrium growth theory, which allows for the systematic analysis of how both population size and body size are determined in pre-industrial societies. The framework holds a number of novel implications.

First, it provides a theoretical explanation for the pervasiveness of "Damuth's law", which stipulates an inverse association between body size and population density. The model replicates Damuth's original finding of a $-3 / 4$ coefficient on body size in the case where total output only depends on land area (i.e., $Y=A X$ with $X$ being land). More generally the theory predicts that the quantitative nature of the allometry would be species specific, and geo-zone specific, in keeping with the evidence.

Second, the model provides a theoretical basis for using data on body size (e.g., height) as a short run indicator of prosperity, as is commonly done (yet without general equilibrium foundations), in the anthropometric history literature.

Third, it provides answers to a series of questions with bearing on the long-run development process. For instance: (1) Why did the introduction of the potato only raise European population size and not average body size? (2) Why did average body size oscillate over the last two millennia? (3) Why did the Neolithic revolution lead to greater population density, yet smaller people?

The present analysis has focused on the pre-industrial society. As a result, an issue of first order importance left open to future research lies in generating a full transition to sustained growth, where the current conceptualization of child quality (i.e., nutrition) plays a central role. Such an account would not only involve a take-off in growth in income per capita. It should also account for the striking regularity that as human societies went through the demographic transition, whereby fertility declines, average stature rises. This transformation may very well be an important element in a fuller understanding of the take-off, and in accounting for the rise in longevity, which currently developed societies have obtained during the last century. 


\section{Appendix A}

The 50 countries for which we have data on body weight are: Armenia (ARM); Benin (BEN); Burkina Faso ( BFA ); Bangladesh (BGD); Bolivia (BOL); Brazil (BRA); Central African Republic (CAF); Cote d'Ivoire (CIV) ; Cameroon (CMR) ;Colombia (COL); Comoros (COM ); Dominican Republic (DOM); Egypt, Arab Rep.( EGY); Eritrea (ERI); Ethiopia(ETH); Gabon (GAB); Ghana (GHA); Guinea (GIN); Guatemala (GTM); Haiti (HTI); India (IND); Jordan (JOR); Kazakhstan (KAZ); Kenya (KEN); Kyrgyz Republic (KGZ); Cambodia (KHM); Morocco(MAR); Madagascar (MDG); Mali (MLI); Mozambique (MOZ); Mauritania (MRT); Malawi (MWI ); Namibia (NAM); Niger (NER ); Nigeria (NGA); Nicaragua (NIC); Nepal (NPL); Peru (PER); Rwanda (RWA); Senegal (SEN); Chad (TCD); Togo (TGO); Turkmenistan (TKM) ; Turkey (TUR); Tanzania (TZA); Uganda (UGA); Uzbekistan (UZB); Yemen, Rep. (YEM); Zambia (ZMB); Zimbabwe (ZWE).

\section{Appendix B}

The basic fact exploited by West et al. (1997) is that the terminal branches of the network (the capillaries) are size-invariant units. From this and the conservation of the fluid as it flows through the system follows that the total number of capillaries is proportional to the metabolic rate. Consider a network of branching vessels with $\nu$ levels of branching and $\eta$ branches per node. Let $k \in\{1, \ldots, \nu\}$ indicate the level of branching. Nature optimizes through choice of the radii $r_{k}$ and lengths $l_{k}$ of the vessels at every level $k$. West et al. have solved the optimization problem given the hydrodynamic and elasticity equations for blood flow and a space-filling condition (requiring that all cells are served). They have shown that the optimal network is a self-similar fractal with two characteristics. (i) It is volume preserving so that $\nu_{k} l_{k}^{3} \approx \nu_{k+1} l_{k+1}^{3}$ where $\nu_{k}$ is the number of branches at level $k$. (ii) It is area preserving so that $\pi r_{k}^{2}=\eta \pi r_{k+1}^{2}$, i.e. the cross-sectional area of a branch at level $k$ equals the sum of the cross-sectional area of branches at the next (lower) level. Noting that $\nu_{k+1} / \nu_{k}=\eta$ one gets two invariant scale factors, $\beta \equiv r_{k+1} / r_{k}=\eta^{-1 / 2}$ and $\gamma \equiv l_{k+1} / l_{k} \approx \eta^{-1 / 3}$. For example, as blood flows down through a bifurcating hierarchy $(\eta=2)$ the radii of vessels decrease with factor $1 / \sqrt{2}$ whereas the length of vessels decreases at rate $1 / \sqrt[3]{2}$.

Finally, West et al. showed that the total volume of blood in an energy minimizing network is proportional to body mass $m$. This feature combined with the fractal nature of the network implies scaling according to (1). To see this calculate the total volume of blood.

$$
V_{b}=\sum_{k=0}^{\nu} \pi r_{k}^{2} l_{k} \eta^{k}=\frac{1-\left(\eta \gamma \beta^{2}\right)^{-(\nu+1)}}{1-\left(\eta \gamma \beta^{2}\right)^{-1}} \eta^{\nu} V_{c} \approx \frac{\left(\gamma \beta^{2}\right)^{-\nu}}{1-\left(\eta \gamma \beta^{2}\right)^{-1}} V_{c}
$$

with $V_{c}$ denoting the volume of a capillary, an invariant unit. Conclude that blood volume and thus mass is proportional to $\left(\gamma \beta^{2}\right)^{-\nu}$ implying that $\log (\nu)$ is proportional to $-\log (m) / \log \left(\gamma \beta^{2}\right)$. The metabolic rate is proportional to the number of capillaries $n^{\nu}$ implying that $\log (B)$ is proportional to $\nu \log (n)$ and thus to $-\log (m) \cdot \log (n) / \log \left(\gamma \beta^{2}\right)$. Insert $\beta$ and $\gamma$ to find that $\log (B)$ is proportional to $3 / 4 \log (m)$ which is Kleiber's law. 


\section{Appendix C}

For stability analysis we evaluate the Jacobian Determinant of system (12) numerically. We have identified $\alpha, \phi$, and $\tau$ as the parameters whose change induces the strongest reaction of dynamic behavior (and, of course, $b$; yet as explained above there is very little range for variation of $b$ ). Figure A shows the eigenvalues of the Jacobian for parameters from Table 2 and alternative $\alpha$ and $\phi$ (left hand side) and alternative $\alpha$ and $\tau$. Inspection lets us conclude that for reasonable parameter values both eigenvalues are absolutely smaller than one, the dynamic system is locally stable. Only if $\alpha$ gets implausibly small and simultaneously $\tau$ is very small, the equilibrium becomes unstable.

Since the arrows of motion continue to point towards the equilibrium, we then obtain the possibility of periodic orbits of body size and population size. We can verify numerically that this case indeed occurs. For example, for $\alpha=0.5$ and $\tau=0.03$, we obtain two-periodic cycles where body mass oscillates perpetually between 58 and $61 \mathrm{~kg}$. Further reduction of $\alpha$ or $\tau$ produces cycles of different periods, irregular cycles, and, finally, explosion. While these are theoretically interesting findings, with respect to a reasonable calibration of the model, local stability is the case of practical relevance.

Figure A: Eigenvalues
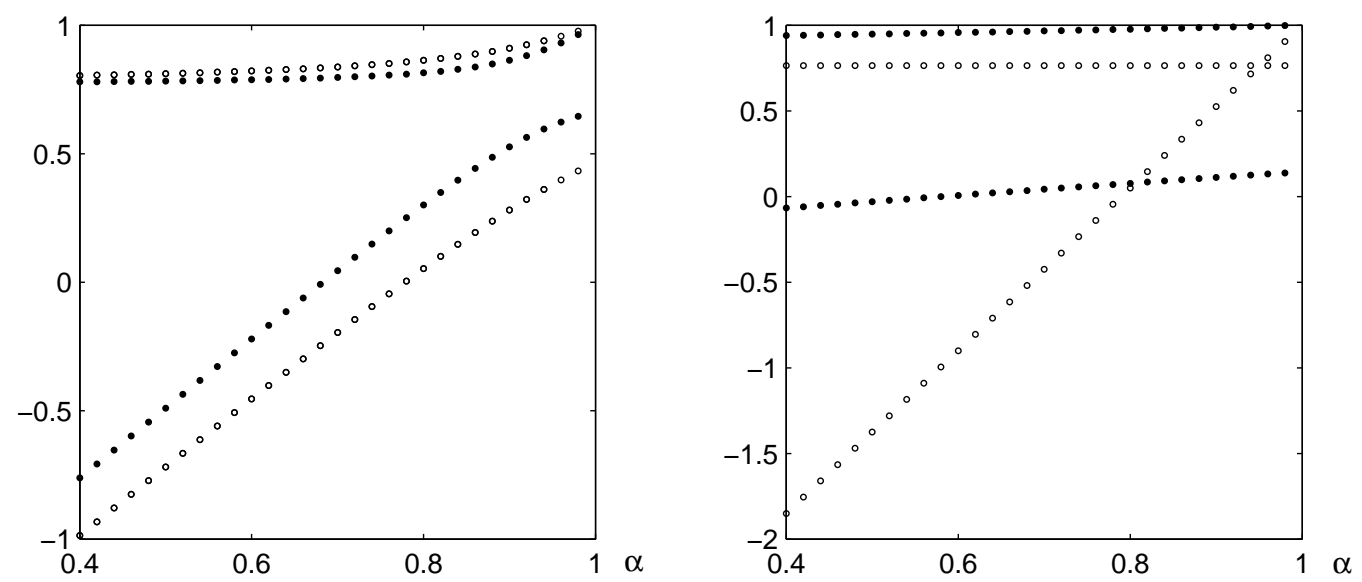

Parameters from Table 2 and alternative values of $\alpha$ and $\phi$. White dots: $\phi=0$; solid dots: $\phi=0.5$. 


\section{References}

Aiyar, S., C-J. Dalgaard and O. Moav, 2008. Technological progress and regress in pre-industrial times, Journal of Economic Growth 13, 125-44

Akachi, Y. and D. Canning, 2007. The height of women in Sub-Saharan Africa: The role of health, nutrition, and income in childhood, Annals of Human Biology 34, 397 - 410.

Apps, P. and R. Rees, 2002, Household production, full consumption and the costs of children, Labor Economics 8, 621-648.

Ashraf, Q. and O. Galor, 2008. Dynamics and Stagnation in the Malthusian Epoch: Theory and Evidence, Working Paper (Brown University)

Becker G., 1960. An economic analysis of fertility. In: Demographic and economic change in developed countries. Conference of the Universities-National Bureau Committee for Economic Research, a Report of the National Bureau of Economic Research. Princeton University Press, Princeton, NJ, pp 209-240

Becker, G., 1992. Fertility and the economy, Journal of Population Economics 5, 181-201.

Behrman, J.R. and M. Rosenzweig, 2004. Returns to birthweight, Review of Economics and Statistics 86, 586-601.

Brody, S., 1945, Bioenergetics and Growth, Van Nostrand-Reinhold, New York.

Brown, J., J. Gillooly, A. Allen, V.M. Savage and G. West, 2004, Towards a metabolic theory of ecology, Ecology 85, 1771-89.

Brinkman, H-J., J.W. Drukker, and B. Slot, 1988. Height and income: A new method for the estimation of historical national income series, it Explorations in Economic History 25, 227-64.

Charnov, E.L., 1991, Evolution of life history variation among female mammals, Proceedings of the National Academy of Sciences of the United States of America 88, 1134-1137.

Charnov, E.L., 1993, Life History Invariants, Oxford University Press, Oxford.

Charnov, E.L. and S.K.M. Ernest, 2006. The offspring - size / clutch - size trade-off in nammals. The American Naturalist 167, 578-82.

Clark, G., 2007, Farewell to Alms: A Brief Economic History of the World, Princeton University Press.

Cole, T.J., 2000, Secular trends in growth, Proceedings of the Nutrition Society 59, 317-324.

Damuth, J., 1981, Population density and body size in mammals, Nature 290, 699-700.

Damuth, J., 1993. Cope's rule, the island rule and the scaling of mammalian population density, Nature 365, p. 748-50.

Darveau, C.A., R.K. Suarez, R.D. Andrews, and P.W. Hochachka, 2002, Allometric cascade as a unifying principle of body mass effects on metabolism, Nature 417, 166-170.

Douglas J.W.B. and H.R. Simpson, 1964, Height in relation to puberty family size and social class: A longitudinal study, The Milbank Memorial Fund Quarterly 42, 20-34.

Duncan, S.R., S.J. Duncan, and S. Scott, 2001, Human population dynamics, Annals of Human Biology 28, 599-615.

Fogel, R.W., 1994, Economic growth, population theory, and physiology: The bearing of longterm processes on the making of economic policy, American Economic Review 84, 369-395. 
Fogel, R.W., 1997, New findings on secular trends in nutrition and mortality: Some implications for population theory, in: Mark Rosenzweig and Oded Stark (eds.), Handbook of Population and Family Economics, Volume 1A, New York, Elsevier.

Galloway, P.R., 1986, Long-term fluctuations in climate and population in the preindustrial era, Population and Development Review 12, 1-24.

Galor, O., 2006, From stagnation to growth: Unified growth theory, in P. Aghion and S. Durlauf (eds.) Handbook of Economic Growth, North Holland, Amsterdam.

Galor, O., 2007, Discrete Dynamical Systems, Springer, Berlin, Heidelberg, New York.

Galor, O. and D. Weil, 1999, From Malthusian Stagnation to Modern Growth, American Economic Review Papers and Proceedings 89, 150-54.

Galor, O. and D. Weil, 2000, Population, technology and growth: From Malthusian stagnation to the demographic transition and neyond, American Economic Review 90, 806-828.

Gustafsson, B. and U. Kjulin, 1994, Time use in child care and housework and the total cost of children, Journal of Population Economics 7, 287-306.

Hagen, E.H., H.C. Barrett, and M.E. Price, 2006, Do human parents face a quality-quantity tradeoff? Evidence from a Shuar Community, American Journal of Physical Anthropology $130,405-418$.

Hansen, G. and E. Prescott, 2002, Malthus to Solow, American Economic Review 92, 1205-1217.

Hanushek, E., 1992. The trade-off between child quality and quantity, Journal of Political Economy 100, 84-117.

Kleiber, M., 1932, Body size and metabolism, Hilgardia 6, 315-353.

Koepke, N. and J. Baten, 2005a, The biological standard of living in Europe during the last two millennia, European Review of Economic History 9, 61-95.

Koepke, N. and J. Baten, 2005b, Climate and its impact on the biological standard of living in north-east, centre-west and south Europe during the last 2000 years, History of Meteorology 2, 147-159.

Komlos, J., 1989. Nutrition and Economic Development in the Eighteenth-Century Habsburg Monarchy, Princeton University Press.

Komlos, J. and J. Baten, 2004, Looking backward and looking forward - Anthropometric research and the development of social science history, Social Science History 28, 191-210.

Kremer, M., 1993, Population growth and technological change: One million B.C. to 1900, Quarterly Journal of Economics 108, 681-716.

Kuh, D.L. and M. Wadsworth M, 1989, Parental height: childhood environment and subsequent adult height in a national birth cohort, International Journal of Epidemiology 18, 663-668.

Kunitz, S., 1987, Making a long story short: A note on mens height and mortality in England from the first through the nineteenth centuries, Medical History 31, 269-80.

Lee, M.L. and D. Loschky, 1987, Malthusian population oscillations, Economic Journal 97, 727-739.

Lucas, R.E. Jr., 2002, The industrial revolution: Past and future, in: Lucas, R.E. Jr., Lectures on Economic Growth, Cambridge, Massachusetts: Harvard University Press.

Nunn, N. and N. Qian, 2008, Columbus's contribution to world population and urbanization: A natural experiment examining the introduction of potatoes, Working Paper (Harvard University). 
Prentice, A.M. and R.G. Whitehead, 1987, The energetics of human reproduction, Symposia of the Zoological Society of London 75, 275-304.

Rosensweig, M. and K. Wolpin, 1980. Testing the quality-quantity fertility model: The use of twin as a natural experiment.Econometrica 48, pp. 227-40.

Sadurkis, A., N. Kabir, J. Wagner, and E. Forsum, 1988, Energy metabolism, body composition, and milk production in healthy Swedish woman during lactation, American Journal of Clinical Nutrition 48, 44-49.

Roff, D.A., 2002. Life History Evolution, Sunderland, MA, Sinauer Associates.

Ruff, C., 2002, Variation in human body size and shape. Annual Review of Anthropology 31, 211-232.

Schneider, R., 1996, Historical note on height and parental consumption decisions, Economics Letters 50, 279-83.

Silventoinen, K., 2003, Determinants of variation in adult body height, Journal of Biosocial Science 35, 263-285.

Smith, C.C. and S.D. Fretwell, 1974, The optimal balance between size and number of offsprings, American Naturalist 108, 499-506.

Steckel, R., 1983, Height and per capita income, Historical Methods 16, 1-7.

Steckel, R., 2008, Heights and human welfare: Recent developments and new directions, NBER working paper No. 14536.

Walker R., M. Gurven, O. Burger and M.J. Hamilton, 2008, The trade-off between number and size of offspring in humans and other primates, Proceedings of the Royal Society 275, 827-33.

Weil, D., 2007, Accounting for the effect of health on economic growth, Quarterly Journal of Economics 122, 1265-1306.

Weir, D.R., 1993, Parental consumption decisions and child health during the early French fertility decline: 1790-1914, Journal of Economic History, 259-74.

West, G.B and J. H. Brown, 2005, The origin of allometric scaling laws in biology from genomes to ecosystems: Towards a quantitative unifying theory of biological structure and organization, Journal of Experimental Biology 208, 1575-92.

West G.B., J. H. Brown and B.J. Enquist, 1997, A general model of the origin of allometric scaling laws in biology, Science 276, 122-26.

West G.B., J. H. Brown and B.J. Enquist, 2001, A general model of ontogenetic growth, Nature 413, 628-31.

Woitek, U., 2003, Height cycles in the 18th and 19th century, Economics and Human Biology 1, 243-257.

Weisdorf, J., 2005, From foraging To farming: Explaining the Neolithic revolution. Journal of Economic Surveys 19, 561-86. 